\title{
Analisis Nilai Tambah Produksi pada Industri Tempe Di Kecamatan Barabai Kabupaten Hulu Sungai Tengah
}

\section{(Analysis of Additional Production Value at Tempe Industry In Barabai District Hulu Sungai Tengah Regency)}

\author{
Azwar Saihani $^{1)}$, Rachman Fitrianoor ${ }^{2)}$ \& Dwi Rahmawati ${ }^{3)}$ \\ Program Studi Agribisnis, Sekolah Tinggi Ilmu Pertanian Amuntai \\ 1)Azwar.saihani63@yahoo.com \\ ${ }^{2)}$ rafi@yahoo.com \\ 3)dwirahmawati@gmail.com
}

\begin{abstract}
ABSTRAK
Penelitian ini memiliki dua tujuan yaitu (i) mengetahui gambaran umum dan (ii) menghitung besaran nilai tambah yang dihasilkan industri tempe di Kecamatan Barabai Kabupaten Hulu Sungai Tengah. Penelitian ini dilakukan pada pengusaha industri tempe yang ada di Kecamatan Barabai Kabupaten Hulu Sungai Tengah. Metode yang digunakan dalam menganalisis data yang tersedia dari pengusaha industri tempe di Kecamatan Barabai Kabupaten Hulu Sungai Tengah adalah dengan menggunakan rumus nilai tambah bruto, nilai tambah netto, dan bahan baku nilai tambah. Perhitungan tersebut terkait dengan peralatan yang digunakan, bahan baku utama, dan bahan baku tambahan yang digunakan dalam proses pembuatan tempe. Berdasarkan hasil penelitian yang dilakukan pada industri kedelai yang ada di Kecamatan Barabai nilai tambah bruto yang dihasilkan dari semua responden sebesar Rp 56.247.500, nilai tambah netto yang dihasilkan adalah sebesar Rp 48.062.500, sedangkan untuk bahan baku nilai tambah sebesar Rp. 125.363 / Kg. Keberadaan industri kedelai di Kecamatan Barabai dapat meningkatkan nilai tambah bagi pengusaha tempe.
\end{abstract}

Kata kunci : Nilai tambah, industri, tempe, netto, bruto.

\section{ABSTRACT}

This research has two objectives, namely to determine soybean industry overview in sub Barabai and calculating the amount of value added generated by the soybean industry in the Barabai District Hulu Sungai Tengah Regency. The research was conducted at tempe existing tempe industrial business in the District Barabai Hulu Sungai Tengah Regency. The method used in analyzing the data available from industry employers in the Barabai District Hulu Sungai Tengah is to use the formula of gross value added, net value added, and value-added raw materials. The calculations associated with the equipment used, the main raw material, and auxiliary raw materials used in the process of making tempe. Based on the results of research conducted on the existing soybean industry in the District Barabai gross value added generated from all respondents of $R p$ 56.247.500, net value added generated amounted to $R p$ 48.062.500, while for value-added raw materials amounting to $R p 125.363 / \mathrm{Kg}$. The existence of the soybean industry in Barabai be able to increase the added value for entrepreneurs tempe.

Keywords : Value added, industry, tempe, netto, bruto.

\section{PENDAHULUAN}

Agribisnis merupakan suatu kesatuan kegiatan usaha yang meliputi salah satu atau keseluruhan dari mata rantai produksi, pengolahan hasil, dan pemasaran yang ada hubungannya dengan pertanian dalam arti luas, yaitu kegiatan usaha yang menunjang kegiatan pertanian dan kegiatan usaha yang ditunjang oleh kegiatan-kegiatan pertanian (Soekartawi, 2010).
Perlunya perkembangan sektor industri, terutama pada hasil-hasil pertanian adalah untuk memberi nilai tambah dari produk pertanian tersebut. Hal ini akan menambah manfaat yang lebih luas baik bagi petani maupun bagi pengusaha industri pengolahan. Seperti industry olahan kedelai tidak hanya mendominasi berbagai makanan tradisional dari jawa, tetapi juga menjadi makanan favorit masyarakat di luar Pulau Jawa bahkan beberapa sudah mencapai pasar 
internasional. Peningkatan daya beli ini dapat dilihat dari data konsumsi kedelai di Indonesia. Rata-rata konsumsi kedelai pada tahun 2004 sebesar 2.015 ton dan proyeksi konsumsi kedelai pada tahun 2011 dapat mencapai 2.466 ton (Warisno, 2010).

Tempe merupakan makanan tradisional Indonesia yang merupakan hasil fermentasi kedelai. Fermentasi tempe terjadi karena aktivitas kapang Rhizophus sp. pada kedelai sehingga membentuk massa yang kompak dan padat (Santoso, 2005). Zulkifli (2012) mendapatkan nilai tambah bruto yang

Tujuan penelitian adalah (i) mengetahui gambaran umum industri tempe di kecamatan Barabai kabupaten Hulu Sungai Tengah, dan (ii) menghitung besaran nilai tambah yang dihasilkan industri tempe di kecamatan Barabai kabupaten Hulu Sungai Tengah.

\section{METODE PENELITIAN}

Penelitian ini dilaksanakan pada usaha industri Tempe yang bertempat di Kecamatan Barabai Kota Kabupaten Hulu Sungai Tengah. Penelitian ini dilakukan mulai tanggal 24 Mei 2013 sampai dengan tanggal 14 Juli 2013.

Data yang dikumpulkan dalam penelitian ini berupa data primer dan data sekunder. Data primer diperoleh dengan cara wawancara langsung dengan pihak perusahaan. Wawancara tersebut berpedoman pada daftar pertanyaan yang telah disediakan. Data sekunder diperoleh dari beberapa dinas atau instansi yang ada relevansinya dengan penelitian ini, serta dari literatur yang mampu menunjang dan berhubungan dengan penelitian ini.

Data yang diperoleh dari responden diolah dan dianalisis dengan metode analisis Keterangan :

$\mathrm{NTbb} \quad=$ Nilai tambah kedelai yang digunakan $(\mathrm{Rp} / \mathrm{Kg})$

$\mathrm{NTb}=$ Nilai tambah bruto

\section{HASIL DAN PEMBAHASAN}

Usaha industri tempe yang ada di Kecamatan Barabai berjumlah 9 orang. Para pengusaha industri tempe kebanyakannya memperoleh bahan baku berupa kedelai di dapat dari usaha keripik ubi sebesar Rp 5.495.000. Nilai tambah Netto yang di dapat sebesar Rp 5.237.500. Sedangkan Nilai tambah per bahan baku yang di dapat sebesar Rp 5.495 per kilogram bahan baku. Dengan adanya agroindustri pengolahan ubikayu menjadi keripik memberikan keuntungan tersendiri bagi petani ubikayu dengan harga yang lebih tinggi, dimana petani dapat menjual ubikayu secara borongan kepada industri keripik ubikayu dengan harga yang lebih tinggi

nilai tambah produksi sesuai dengan tujuan penelitian. Analisis yang dilakukan menggunakan rumus $\mathrm{NTb}=$ nilai tambah bruto $(\mathrm{Rp}), \mathrm{NTn}=$ Nilai tambah netto $(\mathrm{Rp})$, dan $\mathrm{NTbb}=$ Nilai tambah bahan baku ( $\mathrm{Rp} / \mathrm{Kg})$.

Nilai tambah dapat dihitung dengan rumus

a. Nilai Tambah Bruto (NTb)

$$
\begin{aligned}
\mathrm{NTb} & =\mathrm{Na}-\mathrm{Ba} \\
& =\mathrm{Na}-(\mathrm{Bb}+\mathrm{Bp})
\end{aligned}
$$

Keterangan

$\mathrm{NTb}=$ Nilai tambah bruto $(\mathrm{Rp})$

$\mathrm{Na}=$ Nilai produk akhir tempe $(\mathrm{Rp})$

$\mathrm{Ba}=$ Biaya antara $(\mathrm{Rp})$

$\mathrm{Bb}$ = Biaya bahan baku tempe (Rp)

$\mathrm{Bp} \quad=$ Biaya bahan penolong $(\mathrm{Rp})$

b. Nilai tambah netto (NTn)

$\mathrm{NTn}=\mathrm{NTb}-\mathrm{NP}$

Keterangan :

NTn $=$ Nilai tambah netto $(\mathrm{Rp})$

$\mathrm{NTb}=$ Nilai tambah bruto (Rp)

$\mathrm{NP}=$ Nilai penyusutan peralatan

produksi tempe $(\mathrm{Rp})$

c. Nilai Tambah per Bahan Baku

$\mathrm{NTbb}=\mathrm{NTb}: \sum \mathrm{bb}$
$\sum \mathrm{bb}=$ Jumlah kedelai
yang digunakan $(\mathrm{Kg})$

melalui impor, sedikit sekali yang menggunakan kedelai dari daerah sendiri. Kualitas yang bagus dari kedelai yang menyebabkan pengusaha tempe lebih memilih kedelai impor. Harga kedelai sering terjadi penurunan dan kenaikan yang 
tidak menentu, namun kenaikan dan penurunan harga kedelai tidak mempengaruhi usaha industri tempe untuk tetap berproduksi.

Analisis nilai tambah usaha pengolahan kedelai menjadi tempe dilakukan untuk mengetahui besarnya nilai yang ditambahkan pada bahan baku yang digunakan dalam memproduksi tempe.

Nilai tambah dapat dihitung dengan rumus

a. Nilai Tambah Bruto (NTb)

$\mathrm{NTb}=\mathrm{Na}-\mathrm{Ba}$

Keterangan :

$$
=\mathrm{Na}-(\mathrm{Bb}+\mathrm{Bp})
$$

$\mathrm{NTb}=$ Nilai tambah bruto (Rp)

$\mathrm{Na}=$ Nilai produk akhir tempe $(\mathrm{Rp})$

$\mathrm{Ba} \quad=$ Biaya antara $(\mathrm{Rp})$

$\mathrm{Bb}=$ Biaya bahan baku tempe $(\mathrm{Rp})$

$\mathrm{Bp} \quad=$ Biaya bahan penolong $(\mathrm{Rp})$

b. Nilai tambah netto (NTn)

$\mathrm{NTn}=\mathrm{NTb}-\mathrm{NP}$

$\mathrm{NP} \quad=$

Tabel 1. Analisis nilai tambah bruto, nilai tambah netto, nilai tambah bahan baku tempe untuk

lima kali proses produksi di Kecamatan Barabai tahun 2013

\begin{tabular}{|c|c|c|c|c|}
\hline No & Nama Responden & NTb $(\mathrm{Rp})$ & NTn $(\mathrm{Rp})$ & NTbb $(\mathrm{Rp} / \mathrm{Kg})$ \\
\hline 1 & Abdul Hadi & 6.925 .000 & 6.210 .000 & 15.388 \\
\hline 2 & Asad & 7.530 .000 & 6.925 .000 & 15.060 \\
\hline 3 & Bahruddin & 6.705 .000 & 5.620 .000 & 14.900 \\
\hline 4 & H.Muliyani & 6.015 .000 & 4.985 .000 & 15.037 \\
\hline 5 & Kadarudin & 5.165 .000 & 4.560 .000 & 14.757 \\
\hline 6 & M.Aini & 7.750 .000 & 6.970 .000 & 15.500 \\
\hline 7 & Rahmatullah & 9.060 .000 & 8.175 .000 & 14.496 \\
\hline 8 & Selamet & 6.080 .000 & 4.212 .500 & 12.160 \\
\hline 9 & Zainuddin & 3.015 .000 & 2.402 .500 & 12.060 \\
\hline & Jumlah & 58.245 .000 & 50.060 .000 & 129.358 \\
\hline \multicolumn{2}{r}{ Rata-rata } & 6.471 .666 & 5.562 .222 & 14.373 \\
\hline
\end{tabular}

Sumber : Data Primer (diolah), 2013.

Dari Tabel 1 dapat dijelaskan hasil perhitungan analisis nilai tambah yang meliputi nilai tambah bruto, nilai tambah netto, dan nilai tambah bahan baku. Nilai tambah yakni pertambahan nilai suatu komoditi karena adanya input fungsional yang berupa form utility, place utility, time utility. Variabel yang terkait dalam analisis
Keterangan :

NTn = Nilai tambah netto (Rp)

$\mathrm{NTb}=$ Nilai tambah bruto (Rp)

$\mathrm{NP}=$ Nilai penyusutan peralatan

produksi tempe $(\mathrm{Rp})$

c. Nilai Tambah per Bahan Baku

$\mathrm{NTbb}=\mathrm{NTb}: \sum \mathrm{bb}$

Keterangan :

$\mathrm{NTbb}=$ Nilai tambah kedelai yang

digunakan $(\mathrm{Rp} / \mathrm{Kg})$

$\mathrm{NTb}=$ Nilai tambah bruto

$\sum \mathrm{bb}=$ Jumlah kedelai yang digunakan

$(\mathrm{Kg})$

Perhitungan analisis nilai tambah yang dilakukan dalam penelitian ini dimulai dari pengadaan bahan baku, bahan penolong, dan penggunaan peralatan. Hasil perhitungan untuk analisis nilai tambah tempe dapat dilihat pada tabel dibawah ini : 
sebesar Rp 14.496/kg. Sedangkan responden yang memiliki nilai tambah yang paling rendah yakni responden Zainuddin, dengan nilai tambah bruto yakni $\mathrm{Rp}$

\section{KESIMPULAN}

Usaha industri tempe yang ada di Kecamatan Barabai berjumlah 9 industri. Para pengusaha industri tempe memperoleh bahan baku berupa kedelai tidak hanya di Barabai tapi juga dari daerah lain. Harga kedelai sering terjadi penurunan dan kenaikan yang tidak menentu, namun kenaikan dan penurunan harga kedelai tidak mempengaruhi usaha industri tempe untuk tetap berproduksi . Jumlah keseluruhan untuk nilai tambah bruto sebesar Rp 58.245.000 dengan rata-rata sebesar $\mathrm{Rp}$ 6.471.666. Nilai tambah netto secara keseluruhan yakni sebesar Rp 50.060.000 dengan rata-rata sebesar Rp 5.562.222 sedangkan untuk nilai tambah bahan baku secara keseluruhan yakni sebesar $\mathrm{Rp}$ 129.358/Kg dengan rata-rata sebesar Rp 14.373/Kg.
3.015.000, nilai tambah netto $\mathrm{Rp}$ 2.402.500, dan nilai tambah bahan baku yakni Rp $12.060 / \mathrm{kg}$.

\section{DAFTAR PUSTAKA}

Santoso. 2005. Teknologi pengolahan kedelai (Teori dan Praktik). Laboratorium Kimia Pangan Fakultas Pertanian Universitas Widyagama Malang.

Soekartawi. 2010. Agribisnis Teori dan Aplikasinya. PT. Raja Grafindo Persada. Jakarta.

Warisno \& Kres Dahana. 2010. Meraup Untung dari Olahan Kedelai. Agromedia. Jakarta Selatan

Zulkifli. 2012. Analisis pendapatan dan nilai tambah pada agroindustri keripik ubi Di Kecamatan Tanah Luas Kabupaten Aceh Utara. Skripsi. Fakultas Pertanian Universitas Malikussaleh. Aceh Utara. 